\title{
Effect of magnesium sulfate pretreatment on onset and recovery characteristics of cisatracurium
}

\author{
Sang-Hun Kim ${ }^{1,2}$, Keum-Young So ${ }^{1,2}$, and Ki-Tae Jung ${ }^{2}$ \\ Department of Anesthesiology and Pain Medicine, ${ }^{1}$ School of Medicine, Chosun Univeristy, ${ }^{2}$ Chosun University Hospital, Gwangju, Korea
}

Background: To determine how pretreatment with magnesium sulfate $\left(\mathrm{MgSO}_{4}\right)$ potentiates neuromuscular blocking agents. We investigated how the onset and recovery characteristics of cisatracurium are changed by pretreatment with $\mathrm{MgSO}_{4}$.

Methods: After Institutional Review Board approval, a total of 48 ASA I and II patients were devided into 2 groups. Patients in each group received either the $\mathrm{MgSO}_{4} 30 \mathrm{mg} / \mathrm{kg}$ (group $\mathrm{M}$ ) in $0.9 \%$ normal saline (total volume 100 $\mathrm{ml}$ ) or $0.9 \%$ normal saline (control group C) alone intravenously for $15 \mathrm{~min}$ before induction of anesthesia with propofol, remifentanil and cisatracurium $0.15 \mathrm{mg} / \mathrm{kg}$. Anesthesia was maintained with propofol and remifentanil. Electromyographical responses were measured by train-of-four. Lag time, onset time, total recovery time, clinical duration, recovery index, and recovery time were measured. The mean arterial blood pressure, heart rate, and ionized magnesium were also measured.

Results: The lag time and onset time were significantly shorter in the $\mathrm{MgSO}_{4}$ group than the control group $(\mathrm{P}<0.05)$. Recovery index, recovery time, clinical duration, and total recovery time showed no significant differences in the $\mathrm{MgSO}_{4}$ group compared to the control group ( $\mathrm{P}>0.05$ ). Mean arterial pressure was more significantly increased in the $\mathrm{MgSO}_{4}$ group than in the control group at the time point immediately after the administration of $\mathrm{MgSO}_{4}$. Heart rate showed no significant changes in both groups. The concentrations of ionized magnesium were significantly more increased at the all time point $(\mathrm{P}<0.05)$.

Conclusions: $\mathrm{MgSO}_{4}$ results in about $29 \%$ shortening of onset time of cisatracurium $(0.15 \mathrm{mg} / \mathrm{kg})$ without prolongation on the recovery of neuromuscular block. (Korean J Anesthesiol 2012; 62: 518-523)

Key Words: Cisatracurium, Magnesium sulfate, Onset, Recovery.

Received: October 28, 2011. Revised: November 18, 2011. Accepted: November 28, 2011.

Corresponding author: Keum-Young So, M.D., Ph.D., Department of Anesthesiology and Pain Medicine, School of Medicine, Chosun University, Chosun University Hospital, 588, Seasuk-dong, Dong-gu, Gwangju 501-717, Korea. Tel: 82-62-220-3223, Fax: 82-62-223-2333, E-mail: kyso@chosun.ac.kr (C) This is an open-access article distributed under the terms of the Creative Commons Attribution Non-Commercial License (http:// creativecommons.org/licenses/by-nc/3.0/), which permits unrestricted non-commercial use, distribution, and reproduction in any medium, provided the original work is properly cited. 


\section{Introduction}

Magnesium sulffate $\left(\mathrm{MgSO}_{4}\right)$ is widely used during the peri-operative period to treat arrhythmia, asthma and acute respiratory failure, to attenuate blood pressure increases, and to prevent seizures in parturient with pre-eclampsia. $\mathrm{MgSO}_{4}$, which acts as an antagonist at N-methyl-D-aspartate receptors, has an effect on neuromuscular transmission [1]. $\mathrm{MgSO}_{4}$ diminishes the amount of acetylcholine released from the motor nerve terminal, attenuating the excitability of the muscle fiber and reducing the amplitude of the end plate potential. It therefore potentiates the neuromuscular block produced by nondepolarizing neuromuscular blocking agents (NMBAs) [2].

Relatively few studies have been conducted on the effects of $\mathrm{MgSO}_{4}$ administration before induction with NMBAs. Some authors have reported that pre-treatment with $\mathrm{MgSO}_{4}$ increased the speed of onset and prolonged the recovery characteristics of non-depolarizing NMBAs [3,4]. On the other hand, Kussman et al. [5] reported that $\mathrm{MgSO}_{4}$ significantly prolonged the recovery of the neuromuscular block but curiously had no influence on onset time. Rocuronium and cisatracurium are relatively recently introduced non-depolarizing muscle relaxants. Although they have similar hemodynamic effects, cisatracurium has a relatively long onset time, discouraging rapid-sequence induction $[6,7]$. Few reports have been presented on the onset and recovery characteristics of cisatracurium [8].

The purpose of this study was to investigate the effects of magnesium sulfate, given before the induction of anesthesia, on the onset time and recovery characteristics of cisatracurium.

\section{Materials and Methods}

This prospective randomized placebo-controlled trial was approved by the institutional Ethics Committee. Written informed consent was obtained from all patients. We recruited American Society of Anesthesiologists (ASA) physical status I or II patients, aged 18-65 years, scheduled for an elective surgery lasting at least $120 \mathrm{~min}$. The study protocol adhered to published guidelines on pharmacodynamic studies of NMBA [9]. Patients with an allergy to cisatracurium and $\mathrm{MgSO}_{4}$, neuromuscular disease, with expected difficult mask ventilation or intubation, receiving medications known to influence neuromuscular function (for instance, calcium channel blockers, aminoglycosides or phenytoine), with electrolyte abnormalities, with hepatic or renal insufficiency, with a body mass index of $<19$ or $>28$, and who were pregnant or breastfeeding were excluded from the study.

All patients were pre-medicated with intramuscular midazolam $(0.05 \mathrm{mg} / \mathrm{kg}) 30$ minutes before anesthesia. Standard monitoring included an ECG, non-invasive blood pressure, end- tidal partial pressure of carbon dioxide, and peripheral pulse oximetry. Study medications were produced and randomized (using a random number table) by the non-investigating nurse in indistinguishable, numbered syringes.

Patients were allocated to one of two groups. In the $\mathrm{MgSO}_{4}$ group (group $\mathrm{M}$ ), patients received $\mathrm{MgSO}_{4} 30 \mathrm{mg} / \mathrm{kg}$ in $0.9 \%$ normal saline (total volume $100 \mathrm{ml}$ ) intravenously. In the control group (group C), patients received the same volume of $0.9 \%$ normal saline alone. The study drugs were given using a volumetric infusion pump for 15 min before induction of anesthesia. At the end of study drug administration, the intravenous line was flushed, and anesthesia was induced with remifentanil and propofol based on a Minto pharmacokinetic model using a TCI device (Orchestra ${ }^{\circledR}$ Base Primea, FreseniusVial, France) [10]. The targeted effect-site concentrations of propofol and remifentanil for induction were $4 \mu \mathrm{g} / \mathrm{ml}$ and $3 \mathrm{ng} /$ $\mathrm{ml}$, respectively. For the maintenance of anesthesia, a propofol effect-site concentration of $3 \pm 2 \mu \mathrm{g} / \mathrm{ml}$ and a remifentanil effect-site concentration of $3 \pm 0.5 \mathrm{ng} / \mathrm{ml}$ with a $50 \%$ oxygen-air mixture were used.

Neuromuscular function was assessed by electromyography of the adductor pollicis, on the side opposite the blood pressure cuff and intravenous line, with train-of-four using the neuromuscular transmission module and was displayed on an anesthetic monitoring system (Anesthetic Monitoring System $S / 5^{\mathrm{TM}}$, Datex-Ohmeda Inc., Helsinki, Finland). Surface electrodes were placed on cleaned skin over the ulnar nerve on the volar side of the wrist. The arm was kept in the same position during the entire study procedure. After injection of remifentanil $2 \mu \mathrm{g} / \mathrm{kg}$, for over 30 seconds, the stimulus current needed to achieve the maximal response of the adductor pollicis muscle was automatically determined in each patient. The search began with a $10 \mathrm{~mA}$ stimulus and the response was measured. The current was increased in steps of $5 \mathrm{~mA}$ until the increase in the current no longer increased the response. This maximal current was then automatically increased by $15 \%$, resulting in a supramaximal current. If the supramaximal current was not found or the response was too weak, the current was set at $70 \mathrm{~mA}$. Each patient's supramaximal stimulation was applied with $0.2 \mathrm{~ms}$ duration square waves and a 1 second cycle time. After the supramaximal current was obtained and the induction of anesthesia was completed, a bolus dose of cisatracurium $1.5 \mathrm{mg} / \mathrm{kg}$ was administered intravenously. We measured and recorded the onset and recovery characteristics defined as follows: (1) the time in seconds from the start of cisatracurium injection until the first change of $\mathrm{T} 1$ response (lag time; LT); (2) the time in seconds from the start of cisatracurium injection until 95\% depression of T1 response (onset time, OT); (3) the time in minutes from the start of cisatracurium injection until $\mathrm{T} 1$ of the TOF had recovered to $25 \%$ of the control $\mathrm{T} 1$ value 
(clinical duration, CD); (4) the time in minutes between $25 \%$ and $75 \%$ recovery of the control $\mathrm{T} 1$ value (recovery index, RI); (5) the time in minutes between $25 \%$ recovery of the control T1 value and a TOF ratio of 0.9 (recovery time, RT); and (6) the time from the start of cisatracurium injection until a TOF ratio of 0.9 (total recovery time, TRT) $[11,12]$. The mean arterial blood pressure (MAP) and heart rate (HR) were measured at the following time points: before and after study agent's administration, and at 30, 60, 90, 120 min after operation start. Blood samples for ionized magnesium (normal range 1.1$1.7 \mathrm{mg} / \mathrm{dl}$ ) were obtained before and after the study agent's administration, at $120 \mathrm{~min}$ after the start of operation and $24 \mathrm{~h}$ after operation.

Based on studies that reported a $36 \%$ decrease in the onset time of vecuronium with $60 \mathrm{mg} / \mathrm{kg} \mathrm{MgSO}_{4}$ pre-treatment [12], we assumed that a $20 \%$ reduction of onset time with cisatracurium $1.5 \mathrm{mg} / \mathrm{kg}$ with $30 \mathrm{mg} / \mathrm{kg}$ of $\mathrm{MgSO}_{4}$ pretreatment, corresponding to approximately 31 seconds, could be considered clinically significant. With an estimated standard deviation (SD) of 37 seconds, we calculated the necessary sample size using the level of statistical significance as $\alpha=0.05$ and $\beta=0.2$. Twenty-four patients were needed in each group to test our hypothesis.

SPSS (Windows ver. 19.0, SPSS Inc., Chicago, IL) was used for statistical analysis. All measured values were denoted as mean $\pm \mathrm{SD}$, number of patients, or medians (ranges). Age, body weight index, and supramaximal current were analyzed by the Mann-Whitney U test. Height, weight, and lean body weight were analyzed by unpaired two-tailed Student's t-tests. Gender was analyzed by the $\mathrm{x}^{2}$ test. LT, OT, CD, RI, RT, and TRT were analyzed by the Mann-Whitney $U$ test for non-parametric test. Mean arterial pressure, heart rate, and the concentration of ionized magnesium were analyzed by repeated measures of ANOVA, and when a significant intergroup difference

Table 1. Demographic Data, Cisatracurium Dose and Supramaximal Current

\begin{tabular}{lcc}
\hline & Group C (n=24) & Group M (n=24) \\
\hline Gender (M/F) & $11 / 13$ & $11 / 13$ \\
Age (yr) & $45.7 \pm 13.5$ & $41.0 \pm 14.3$ \\
Height (cm) & $163.5(151-178)$ & $165.5(148-181)$ \\
Weight (kg) & $64.4(49-76)$ & $64.0(49-84)$ \\
LBW (kg) & $49.5(38-59)$ & $48.8(38-64)$ \\
BMI & $23.8 \pm 2.4$ & $23.4 \pm 2.5$ \\
Supramaximal current (mA) & $31.2 \pm 10.4$ & $31.6 \pm 8.5$
\end{tabular}

Values are expressed as mean $\pm \mathrm{SD}$, numbers of patient or medians (ranges). There are no significant differences between groups. In the $\mathrm{MgSO}_{4}$ group (group $\mathrm{M}$ ), patients received $\mathrm{MgSO}_{4} 30 \mathrm{mg} / \mathrm{kg}$ in $0.9 \%$ normal saline (total volume $=100 \mathrm{ml}$ ) intravenously. In the control group (group $\mathrm{C}$ ), patients received the same volume of $0.9 \%$ normal saline alone. LBW: lean body weight, BMI: body mass index. was found, the Mann-Whitney U test was used to compare the groups at individual time points. $\mathrm{P}$ values $<0.05$ were considered statistically significant.

\section{Results}

A total of 48 patients received the assigned study treatment and no patients were withdrawn due to refusal, missed data or adverse effects during the study.

No significant differences in age, gender, height, weight, lean body weight, body weight index, and supramaximal current were found between the groups (Table 1).

In group $\mathrm{M}$, the lag time and onset time were significantly shorter than in group $\mathrm{C}(\mathrm{P}<0.05$, Fig. 1). he median (ranges) lag time and onset time was $43.7(30-83)$ vs. $68.5(40-110)$, and $101.5(75-225)$ vs. 150 (93-240) seconds in groups $M$ and $\mathrm{C}$, respectively. However, there were no significant differences of Recovery index, recovery time, clinical duration, and total recovery time in both groups (Fig. 2). Recovery index, recovery time, clinical duration, and total recovery time were $16.5(7-27)$ vs. $16.0(7-23), 40.7(21-53)$ vs. $41.3(31-49), 71.5(44-89)$ vs. 78.50 (44-88), and $116.0(77-138)$ vs. $118.1(81-132)$ minutes in groups $\mathrm{M}$ and $\mathrm{C}$, respectively.

Mean arterial pressure was more significantly increased in the $\mathrm{MgSO}_{4}$ group than in the control group at the time just after administration of $\mathrm{MgSO}_{4}(\mathrm{P}<0.05$, Fig. 3$)$. Heart rate showed no

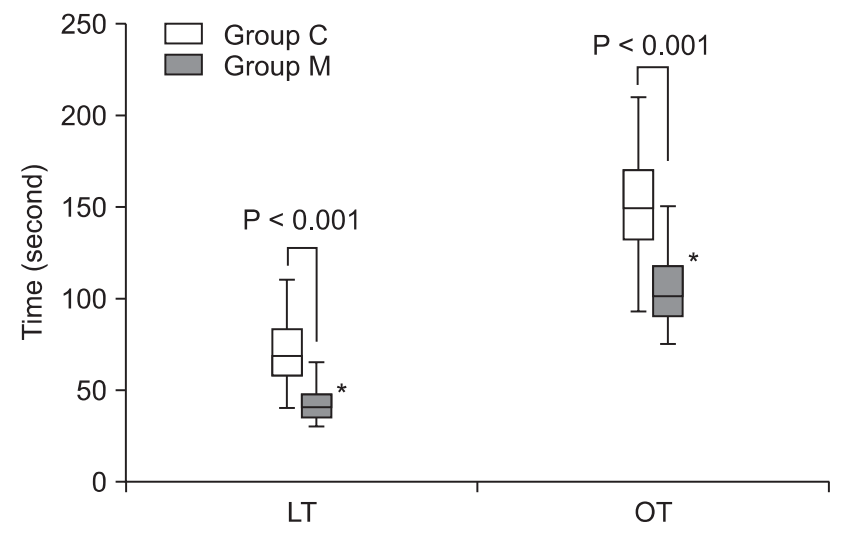

Fig. 1. Lag time (LT) and onset time (OT). LT and OT were significantly shorter in group $\mathrm{M}$ than in group C. LT is the time in seconds from the start of cisatracurium injection until the first change of single twitch response. OT is the time until 95\% depression of the single twitch. In the $\mathrm{MgSO}_{4}$ group (group $\mathrm{M}$ ), patients received $\mathrm{MgSO}_{4} 30 \mathrm{mg} / \mathrm{kg}$ in $0.9 \%$ normal saline (total volume $=100 \mathrm{ml}$ ) intravenously. In the control group (group C), patients received the same volume of $0.9 \%$ normal saline alone. White symbol, magnesium; Grey symbol with polka dots, control. The box-and-whisker plots show 10th and 90th percentiles, lower and upper quartiles, medians (horizontal bars) and means (circles). ${ }^{*} \mathrm{P}<0.05$ compared with Group C. 
significant changes in both groups (Fig. 3). The concentrations of ionized magnesium were significantly more increased at the all time point $(\mathrm{P}<0.05$, Fig. 4).

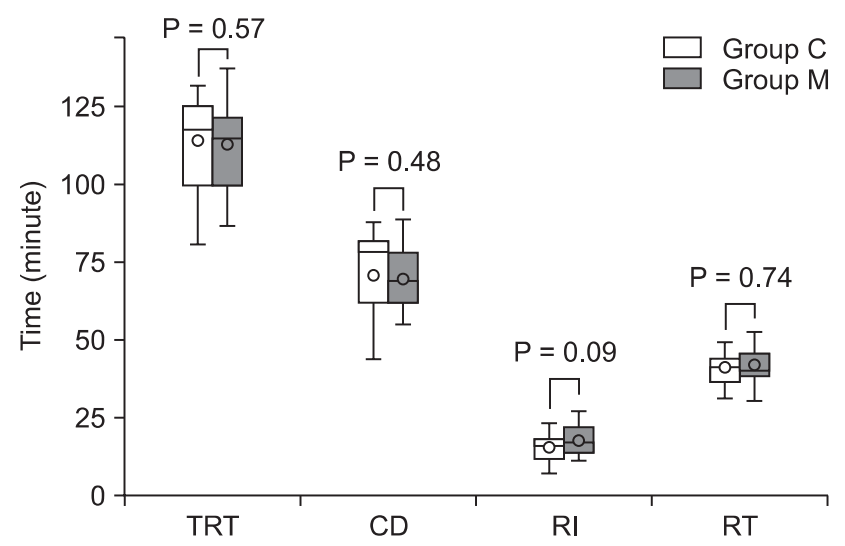

Fig. 2. Recovery characteristics. There were no significant differences between groups in all recovery findings. Total recovery time (TRT) is the time from the start of cisatracurium injection until TOF ratio $=0.9$. Clinical duration $(\mathrm{CD})$ is the time in minutes from the start of cisatracurium injection until T1 of the TOF had recovered to $25 \%$ of the final $\mathrm{T} 1$ value. Recovery index (RI) is the time in minutes between $25 \%$ and $75 \%$ recovery of the final $\mathrm{T} 1$ value. Recovery time (RT) is the time in minutes between $25 \%$ recovery of the final T1 value and a TOF ratio of 0.9. In the $\mathrm{MgSO}_{4}$ group (group M), patients received $\mathrm{MgSO}_{4} 30 \mathrm{mg} / \mathrm{kg}$ in $0.9 \%$ normal saline (total volume $=100$ $\mathrm{ml}$ ) intravenously. In the control group (group C), patients received the same volume of $0.9 \%$ normal saline alone. White symbol, magnesium; Grey symbol with polka dots, control. The box-andwhisker plots show 10th and 90th percentiles, lower and upper quartiles, medians (horizontal bars) and means (circles).

\section{Discussion}

This study reveals that pretreatment of $\mathrm{MgSO}_{4}$ significantly hastens the onset time of cisatracurium without significantly prolonging the recovery characteristics and does not influence the mean arterial pressure and heart rate. Furthermore, although the concentration of the blood ionized magnesium is significantly increased after the administration of $\mathrm{MgSO}_{4}$, there was no adverse effect in any of the patients.

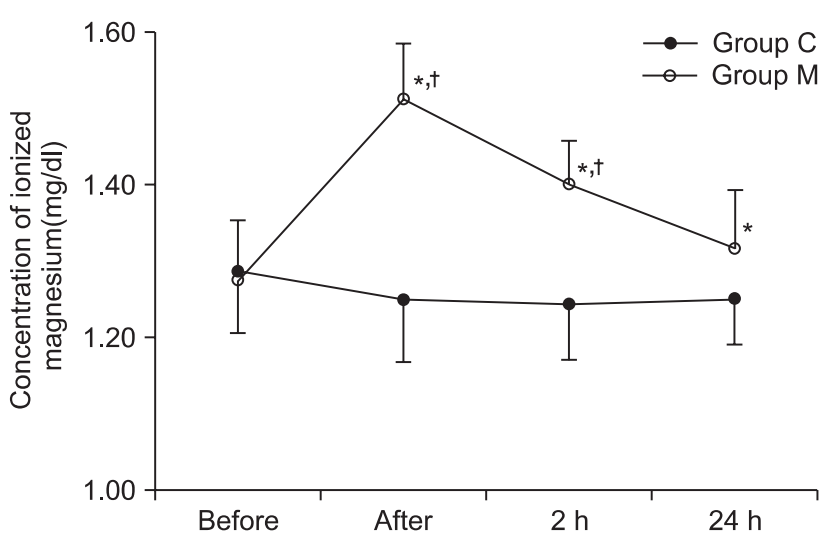

Fig. 4. The concentration of ionized magnesium. There were significant increases of the concentration of ionized magnesium in group $\mathrm{M}$ at all time points. In the $\mathrm{MgSO}_{4}$ group (group $\mathrm{M}$ ), patients received $\mathrm{MgSO}_{4} 30 \mathrm{mg} / \mathrm{kg}$ in $0.9 \%$ normal saline (total volume $=100$ $\mathrm{ml}$ ) intravenously. In the control group (group C), patients received the same volume of $0.9 \%$ normal saline alone. Before: before administration of study agents. After: immediately administration of study agents. $2 \mathrm{~h}$ and $24 \mathrm{~h}$ : the time at $2 \mathrm{~h}$ after operation start and postoperative $24 \mathrm{~h} . * \mathrm{P}<0.05$ is compared with Group $\mathrm{C} .{ }^{\dagger} \mathrm{P}<0.01$ is compared before injection of study agents within each groups.
A

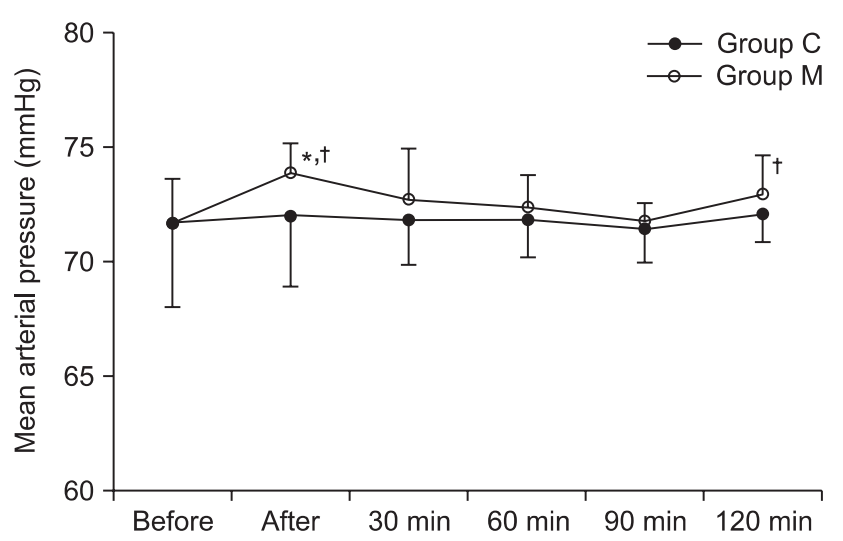

B

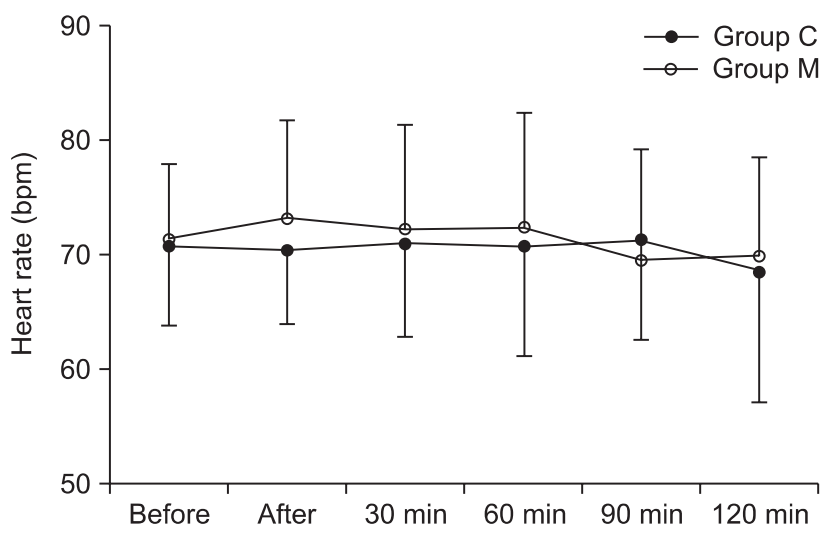

Fig. 3. Mean arterial pressure (A) and heart rate (B). There were no significant differences between groups except mean arterial pressure increased immediately after administration of $\mathrm{MgSO}_{4}$. In the $\mathrm{MgSO}_{4}$ group (group M), patients received $\mathrm{MgSO}_{4} 30 \mathrm{mg} / \mathrm{kg}$ in $0.9 \%$ normal saline (total volume $=100 \mathrm{ml}$ ) intravenously. In the control group (group C), patients received the same volume of $0.9 \%$ normal saline alone. Before: before administration of study agents. After: immediately after administration of study agents. 30, 60, 90 and 120 min: the time at 30, 60, 90 and 120 min after operation start. ${ }^{*} \mathrm{P}<0.05$ is compared with Group C. ${ }^{\dagger} \mathrm{P}<0.01$ is compared before injection of study agents within each groups. 
After pre-treatment with $\mathrm{MgSO}_{4}$, the hastened onset time and prolonged recovery characteristics of NMBAs were observed [3,4]. Fuchs-Buder et al. [3] reported that $\mathrm{MgSO}_{4} 40$ $\mathrm{mg} / \mathrm{kg}$ as an infusion over 15 minutes significantly accelerated the onset time and prolonged the recovery index of vecuronium. Pretreatment with $\mathrm{MgSO}_{4} 30 \mathrm{mg} / \mathrm{kg}$ within 5 minutes also increased the speed of onset and prolonged the recovery index of atracurium [4]. Telci et al. [13] found that the clinical duration and time of TOF $>0.7$ of vecuronium was significantly longer after $30 \mathrm{mg} / \mathrm{kg}$ of $\mathrm{MgSO}_{4}$ followed by $10 \mathrm{mg} / \mathrm{kg} / \mathrm{h}$ continuous infusion. Different doses of $\mathrm{MgSO}_{4}$ as an infusion markedly reduced NMBA consumption, which resulted from the reduced $\mathrm{ED}_{50}$ and $\mathrm{ED}_{90}$ of the NMBAs [3,14]. Schulz-Stubner et al. [14] concluded that mivacurium consumption was markedly reduced from 0.01 to $0.008 \mathrm{mg} / \mathrm{kg} / \mathrm{min}$ in patients receiving $\mathrm{MgSO}_{4}$ infusion. In contrast to these results, Gupta et al. [15] reported that the onset time of rocuronium was unaffected by a $30 \mathrm{mg} / \mathrm{kg}$ bolus of $\mathrm{MgSO}_{4}$ following infusion before induction of anesthesia, but the clinical duration was significantly longer in the $\mathrm{MgSO}_{4}$ group. Kussman et al. [5] reported that $\mathrm{MgSO}_{4}$ $60 \mathrm{mg} / \mathrm{kg}$, injected 1 minute before rocuronium, significantly prolonged the clinical duration of the neuromuscular block but curiously had no influence on the onset time.

In this study, pretreatment with $\mathrm{MgSO}_{4}$ showed conflicting results on the onset time and recovery characteristics, in contrast to previous reports $[3,5,13,15]$. The reasons for this differential effect remain obscure. Our results for the onset time were similar to previously reported results [3,4], except for Kussman's report [5]. Kussman et al. [5] speculated that the differences in the effect of magnesium pretreatment on the onset time reflected differences in the pharmacodynamic properties; the shorter the baseline onset time of the NMBA, such as rocuronium, the less effect $\mathrm{MgSO}_{4}$ pre-treatment would have on its reduction. However, they ignored the fact that the effect of $\mathrm{MgSO}_{4}$ on the neuromuscular endplate was both concentration- and time-dependent and that at least 4-6 minutes were necessary to reach the motor nerve terminal in a concentration high enough to interfere with the NMBAs $[12,16]$. In other words, after a rapid bolus injection immediately before rocuronium, the magnesium ions have no opportunity to reach the motor nerve terminal in a concentration that is high enough to interfere with rocuronium. Consequently, an $\mathrm{MgSO}_{4}$ infusion with enough time to interfere with NMBAs, rather than a bolus injection immediately before the rocuronium, should impact on the NMBAs. $\mathrm{MgSO}_{4}$ may accelerate the transportation of NMBAs to the motor nerve terminal by increasing peripheral blood flow because of its vasodilatation effect [12]. MAP usually decreased after $\mathrm{MgSO}_{4}$ administration; however, the cardiac output and cardiac index were significantly increased due to the consequence of the increase in HR as well as the reduced ventricular afterload $[17,18]$. In our study, we detected that the MAP and HR were increased immediately after $\mathrm{MgSO}_{4}$ administration and we assumed that this effect influenced the onset time of cisatracurium resulting from the increasing cardiac output. Our results on the recovery characteristics were not anticipated because the majority of previous studies reported that $\mathrm{MgSO}_{4}$ pre-treatment prolonged the recovery $[3-5,8,12,13,19]$. One explanation for the differences between previous reports and our study may be the differences in the dose responses of $\mathrm{MgSO}_{4}$. Some authors used the infusion of $\mathrm{MgSO}_{4}$ from 40 to $60 \mathrm{mg} / \mathrm{kg}$, for over $15 \mathrm{~min}[3,12]$, others used the single bolus dosed from 30 to $70 \mathrm{mg} / \mathrm{kg}$ and continuous infusion during the operation $[8,15]$. Fuchs-Buder et al. [3] reported that the ionized concentration after the end of $40 \mathrm{mg} /$ $\mathrm{kg} \mathrm{MgSO}_{4}$ infusion was $1.08 \mathrm{mmol} / \mathrm{L}$ and that $\mathrm{MgSO}_{4}$ increased the neuromuscular potency of rocuronium. Pinard et al. [8] reported that the ionized magnesium concentration after the end of $70 \mathrm{mg} / \mathrm{kg} \mathrm{MgSO}$ infusion was $1.28 \mathrm{mmol} / \mathrm{L}$ and that the ionized magnesium concentration on arrival at the intensive care unit was $1.11 \mathrm{mmol} / \mathrm{L}$, resulting from the continuous infusion of $\mathrm{MgSO}_{4}$ during the operation. Their plasma concentration might be higher than the ionized concentration. Plasma concentrations of magnesium more than $2.5 \mathrm{mmol} /$ L produce a neuromuscular blockade [1]. In our study, the ionized concentrations were 1.51 and $1.40 \mathrm{mg} / \mathrm{dl}$ (0.6-0.62 $\mathrm{mmol} / \mathrm{L}$ ) after the end of infusion and $120 \mathrm{~min}$ after operation. We assumed that the concentration of ionized magnesium did not last long enough to prolong the recovery characteristics, because we used a smaller dose of $\mathrm{MgSO}_{4}(30 \mathrm{mg} / \mathrm{kg})$ without continuous infusion.

In terms of safety, Fuchs-Buder et al. [3] reported that this was clinically safe as no symptoms of muscle weakness were observed. Telci et al. [13] and Schulz-Stubner et al. [14] also demonstrated that magnesium infusion was well tolerated, with no signs of muscle weakness. Although our results on the concentration of ionized magnesium after the administration of $\mathrm{MgSO}_{4} 30 \mathrm{mg} / \mathrm{kg}$ were higher than those of the control group, they were in the normal ranges at the all time points of study without adverse effects such as heat or burning sensations, an acceleration of the heart rate and arrhythmia.

The dose of $\mathrm{MgSO}_{4}$ and the timing of administration were chosen arbitrarily. The timing and duration of administration were taken from a previously published $\mathrm{MgSO}_{4}$-vecuronium interaction study [3]. Many authors have used from 30 to $70 \mathrm{mg} /$ $\mathrm{kg}$ of $\mathrm{MgSO}_{4}$ and most authors reported that these doses were effective to reduce the onset time and prolong the recovery index without any significant side effects $[3-5,8,12,13,19]$. Therefore we decided to use $30 \mathrm{mg} / \mathrm{kg} \mathrm{MgSO}_{4}$ to evaluate the effect on the onset time and recovery characteristics and to avoid clinical adverse effects even if all doses were safe. 
As an alternative to succinylcholine, high doses of NMBAs have been used for rapid sequence intubation. $1.5 \mathrm{mg} / \mathrm{kg}$ of cisatracurium $\left(3 \times \mathrm{ED}_{95}\right)$ provided intubation conditions within 90 seconds and its mean onset time was 3.4 minute, which was not sufficient as an alternative to succinylcholine [20]. Even if an excessively high dose of NMBA prolongs the duration of the neuromuscular block in a dose-dependent manner, which may not be acceptable in every surgical setting, it is not considered for cisatracurium because it is dose-independent in terms of recovery. In our $\mathrm{MgSO}_{4}$-cisatracurium interaction study, the mean onset time was 1.8 minutes, which was significantly hastened compared with $1.5 \mathrm{mg} / \mathrm{kg}$ of cisatracurium. We assumed that the $\mathrm{MgSO}_{4}$-cisatracurium combination could provide intubation conditions within 60 seconds and was sufficient as an alternative for succinylcholine. However, the limitation of our study is that we did not measure the intubation conditions to determine whether $\mathrm{MgSO}_{4}$-cisatracurium combination can alternate for succinylcholine.

In conclusion, $\mathrm{MgSO}_{4}$ shortens the onset time of cisatracurium without significant prolongation of the recovery characteristics of cisatracurium. In addition, we suggest that further investigation is required on different doses of $\mathrm{MgSO}_{4}{ }^{-}$ cisatracurium combination to determine whether they can serve as an alternative to succinylcholine for rapid sequence intubation.

\section{Acknowledgments}

This study was supported by research funds from Chosun University, 2010.

\section{References}

1. James MF. Clinical use of magnesium infusions in anesthesia. Anesth Analg 1992; 74: 129-36.

2. Naguib M, Lien CA. Pharmacology of muscle relexants and their antagonists. In: Miller's anesthesia. 7th ed. Edited by Miller R. Philladelphia, Churchill Livingston. 2010, pp 859-911.

3. Fuchs-Buder T, Wilder-Smith OH, Borgeat A, Tassonyi E. Interaction of magnesium sulphate with vecuronium-induced neuromuscular block. Br J Anaesth 1995; 74: 405-9.

4. Wu HL, Ye TH, Sun L. Effects of atracurium pretreatment with magnesium on speed of onset, duration, and recovery of neuromuscular blockade. Zhongguo Yi Xue Ke Xue Yuan Xue Bao 2009; 31: 73-6.

5. Kussman B, Shorten G, Uppington J, Comunale ME. Administration of magnesium sulphate before rocuronium: effects on speed of onset and duration of neuromuscular block. Br J Anaesth 1997; 79:
122-4.

6. Lin SP, Chang KY, Chen YJ, Lin SM, Chang WK, Chan KH, et al. Priming with rocuronium to accelerate the onset time of cisatracurium during intubation. J Chin Med Assoc 2009; 72: 15-9.

7. Amin AM, Mohammad MY, Ibrahim MF. Comparative study of neuromuscular blocking and hemodynamic effects of rocuronium and cisatracurium under sevoflurane or total intravenous anesthesia. Middle East J Anesthesiol 2009; 20: 39-51.

8. Pinard AM, Donati F, Martineau R, Denault AY, Taillefer J, Carrier M. Magnesium potentiates neuromuscular blockade with cisatracurium during cardiac surgery. Can J Anaesth 2003; 50: 172-8.

9. Fuchs-Buder T, Claudius C, Skovgaard LT, Eriksson LI, Mirakhur RK, Viby-Mogensen J. Good clinical research practice in pharmacodynamic studies of neuromuscular blocking agents II: the Stockholm revision. Acta Anaesthesiol Scand 2007; 51: 789-808.

10. Minto CF, Schnider TW, Egan TD, Youngs E, Lemmens HJ, Gambus $\mathrm{PL}$, et al. Influence of age and gender on the pharmacokinetics and pharmacodynamics of remifentanil. I. Model development. Anesthesiology 1997; 86: 10-23.

11. Schmidt J, Muenster T, Wick S, Forst J, Schmitt HJ. Onset and duration of mivacurium-induced neuromuscular block in patients with Duchenne muscular dystrophy. Br J Anaesth 2005; 95: 769-72.

12. Czarnetzki C, Lysakowski C, Elia N, Tramer MR. Time course of rocuronium-induced neuromuscular block after pre-treatment with magnesium sulphate: a randomised study. Acta Anaesthesiol Scand 2010; 54: 299-306.

13. Telci L, Esen F, Akcora D, Erden T, Canbolat AT, Akpir K. Evaluation of effects of magnesium sulphate in reducing intraoperative anaesthetic requirements. Br J Anaesth 2002; 89: 594-8.

14. Schulz-Stubner S, Wettmann G, Reyle-Hahn SM, Rossaint R. Magnesium as part of balanced general anaesthesia with propofol, remifentanil and mivacurium: a double-blind, randomized prospective study in 50 patients. Eur J Anaesthesiol 2001; 18: 723-9.

15. Gupta K, Vohra V, Sood J. The role of magnesium as an adjuvant during general anaesthesia. Anaesthesia 2006; 61: 1058-63.

16. Hubbard JI, Jones SF, Landau EM. On the mechanism by which calcium and magnesium affect the release of transmitter by nerve impulses. J Physiol 1968; 196: 75-86.

17. Puri GD, Marudhachalam KS, Chari P, Suri RK. The effect of magnesium sulphate on hemodynamics and its efficacy in attenuating the response to endotracheal intubation in patients with coronary artery disease. Anesth Analg 1998; 87: 808-11.

18. Critelli G, Ferro G, Peschle C, Perticone F, Rengo F, Condorelli M. Myocardial contractility after injection of prolonged infusion of magnesium sulphate. Acta Cardiol 1977; 32: 65-73.

19. Okuda T, Umeda T, Takemura M, Shiokawa Y, Koga Y. Pretreatment with magnesium sulphate enhances vecuronium-induced neuromuscular block. Masui 1998; 47: 704-8.

20. Bluestein LS, Stinson LW Jr, Lennon RL, Quessy SN, Wilson RM. Evaluation of cisatracurium, a new neuromuscular blocking agent, for tracheal intubation. Can J Anaesth 1996; 43: 925-31. 